\title{
La Cobertura del Comercio Electrónico
}

The e-commerce coverage

\author{
Ana Sofía Rivera - Suarez ${ }^{a}$, Oscar Reyes - Grande ${ }^{b}$
}

\begin{abstract}
:
E-commerce is one of the ways in which companies have managed to penetrate their various processes. The evolution of communication technologies in a globalized society has meant that the way of getting products and services to new clients, produces a greater coverage for their home businesses, thus achieving a negotiation. As it was in the principles of commerce, today e-commerce has presented new ways of making exchanges, without leaving out the value that is given to each product, but with a vision more attached to the current needs of the consumer society. However, the possibility of achieving great results in electron ic commerce are very broad, but the question now is: How far will the scope of this economic, social and productive activity go?
\end{abstract}

\section{Keywords:}

Comercio electrónico, TIC, comercialización, negociación, pagos.

\section{Resumen:}

El comercio electrónico es una de las maneras en las que las empresas han logrado incursionar en sus diversos procesos. La ev olución de las tecnologías de la comunicación en una sociedad globalizada, ha hecho que la forma de hacer llegar productos y servicios a clientes nuevos, produzca una cobertura mayor para sus empresas de origen, logrando con ello que se concrete una negociación. Como fue en los principios del comercio, hoy el e-commerce ha presentado nuevas formas de hacer intercambios, sin dejar fuera el valor que se le da a cada producto, pero con una visión más apegada a las necesidades actuales de la sociedad consumidora. Sin embargo, la posibilidad de lograr grandes resultados en el comercio electrónico son muy amplias, pero, la duda ahora es, ¿Hasta dónde van a llegar los alcances de esta actividad económica, social y productiva?

\section{Palabras Clave:}

E-commerce, TIC, commercialization, negotiation, payments

\section{Introducción}

A lo largo de la historia el comercio ha jugado un papel muy importante en la sociedad ya que es una de las bases fundamentales que sustentan el crecimiento en la economía de un país. Pero ¿Cuándo surgió el comercio y por qué? Si bien se ha dicho que esta actividad nació por las necesidades que el hombre tenían para ser autosuficiente.

Las primeras civilizaciones comenzaron a ejercer esta actividad mediante el "Trueque" el cual consistía en el intercambio de mercancías por otras de igual valor y con ello satisfacerse, comenzaron con granos, semillas, frutos, vegetales, algunos metales e incluso ganado, con el paso de los años esta práctica fue evolucionando, ya no solo se trataba de intercambios de bienes sino también de pagos, estos en un inicio no se realizaban con dinero físico como lo es ahora en la actualidad sino que se realizaban mediante productos, los cuales determinaban con valores diferentes. Al poco tiempo surgió la moneda, esta contribuyo a la población de manera efectiva, pues permitía una mayor adquisición de productos. El cambio cada vez fue más notorio, y las necesidades de los seres humanos aún más, pues ya no se trataban solo de la adquisición de bienes sino también de servicios.

El comercio floreció de manera positiva y con ellos nuevas formas de distribuir aquellos bienes, anteriormente el

\footnotetext{
autor de Correspondencia, Universidad Autónoma del Estado de Hidalgo, Escuela Superior de Atotonilco de Tula, Email: oscar_reyes9579@uaeh.edu.mx

b Universidad Autónoma del Estado de Hidalgo, Escuela Superior de Atotonilco de Tula, Email: sofia.suarezrivera@gmail.com
} 
proceso de comercialización se realizaba de manera personal, es decir, las personas conocían el producto, podía verlo y tocarlo para determinar si el producto era de su agrado o no. Pero ¿Qué sucedía con las personas que no tenían acceso de manera personal a los productos? Es en ese momento donde surge la venta por Catálogo, el cual funcionaba con imágenes ilustrativas que permitía a los individuos ver los productos y posibilitaba la compra y venta de los mismos. Pero incluso así no era suficiente para ellos, ya que por medio de esta herramienta los compradores no tenían la certeza de que dicha mercancía fuera realmente como ahí se observaba, por lo cual se tuvo que recurrir a nuevos métodos.

\section{Desarrollo}

La apertura de nuevas forma de comercializar revoluciono la era del trueque. En la década de los años 70s las ideas innovadoras salieron a flote y surgieron los primeros ordenadores que proporcionaban una transmisión de datos y que con ayuda de las televisoras contribuyeron a mejorar el proceso de la venta por catálogo, ya que por ese medio se observaba de manera más detallada los productos, exhibían sus atributos y características para hacerlos más atractivos a los consumidores.

A partir de que la tecnología avanzo, nacieron enlaces que brindaron grandes beneficios a los individuos, como lo fueron las primeras páginas web, que no solo permitían la comunicación entre los personas sino que fue la forma en la que se transformó la comercialización a nivel mundial. De este modo nació el comercio electrónico, el cual hasta el momento ha sido una de las maneras más prácticas de compra-venta en cualquier tipo de producto, sin importar el tamaño, peso, costo, etc.

Aunque no solo cuenta con esas funciones, sino también es una de las fuentes más importantes en materia de publicidad y logística, pues es necesario que mediante estas dos herramientas el producto se comercialice de manera positiva, en cuanto a la publicidad, esta debe lograr que la mercancía sea atractiva para los consumidores, llame su atención e incluso que cause diversas sensaciones en ellos, respecto al área logística, esta se encarga de todos los procesos de empaque y traslado del producto para que llegue a su destino en tiempo y forma para que satisfaga la necesidad del consumidor.

Con el paso del tiempo los seres humanos se adoptaron a los cambios tecnológicos y la constante interacción con ellos, los hizo que formaran parte de su vida cotidiana, hoy en día la mayoría de las personas pasan una gran parte su tiempo frente a una pantalla, ya sea en las redes sociales, en páginas o sitios web que les proporcionen alguna información de interés o incluso jugando, pero en la mayoría de las ocasiones en estos portales electrónicos, por lo menos una vez suele aparecer algún anuncio publicitario referente a algún producto e incluso de alguna tienda virtual, las cuales en algún momento del nuestra vida nos han sido de gran ayuda.

En la actualidad existen una gran variedad de plataformas o tiendas online donde se puede adquirir todo tipo de productos, las más conocidas son Amazon, eBay, MercadoLibre, Liverpool, Walmart, entre otras, las cuales proporcionan a los usuarios productos y servicios de manera confiable y a precios accesibles.

El comercio electrónico ha favorecido en muchos aspectos a la sociedad respecto del comercio tradicional, pues este nos permite tener canales adicionales de ventas, abrirnos a nuevos mercados y ampliar nuestras posibilidades de negocio, pero no siempre se tienen los mismos resultados para todos, así como existen ventajas también existen desventajas que este nos proporciona.

Respecto de las ventajas del comercio electrónico, una de las principales, es que la plataforma está a la vista de muchos usuarios, no importa en qué parte del mundo se encuentre la persona o el cliente, este puede ver la variedad de productos que se encuentran exhibidos en la página web, puede observarlos a detalle, incluso se tiene un acceso más rápido sobre lo que está buscando, no es necesario que este busque entre tantas mercancías, con solo teclearlo el producto aparece, Así mismo proporciona un ahorro de tiempo tanto para el comprador como para el vendedor, pues ya no es necesario que el usuario se dirija a distintos lugares, por ejemplo: anteriormente cuando una persona que era dueña de algún restaurante requería de alguna especie o ingrediente para preparar algún platillo exótico tenía que salir a buscar a diversas tiendas ese producto, para comprar precios y calidad e incluso en ocasiones no lograba encontrar lo que requería y ahora gracias al comercio electrónico tiene la posibilidad de encontrar los productos que necesite sin necesidad de salir de su establecimiento, y además cuenta con una gran variedad de sitios en los que puede encontrar más rápido su producto. Al igual proporciona un ahorro para los vendedores en costos de mantenimiento en comparación de un negocio tradicional, se le brinda más información a los usuarios acerca de un producto, facilita la implementación y desarrollo sobre estrategias de publicidad, al igual facilita la comparación de precios respecto a otras plataformas para determinar cuál es la más adecuada para comprar, cuenta con diferentes formas para realizar las transacciones de pago, cuenta con una variedad de formas de envió y en algunas 
plataformas proporcionan asesorías respecto al producto que se va a adquirir.

Y respecto de las desventajas, en el comercio electrónico como en el comercio tradicional, existe mucha competencia, Por ejemplo: la mayoría de los usuarios puede crea una plataforma en la cual proporcione los mismos servicios y productos que otra. Así mismo la desconfianza que proporcionan algunas páginas web, esto debido a que no son muy reconocidas o que los productos que ofertan no son los mismos que se le envían al comprador, ya que estos en ocasiones no se conforman solo con ver virtualmente el producto, sino que requieren de algo más, como sentirlo e incluso descubrir cuál es su aroma.

Los costos de envió que algunas plataformas estipulan son muy altos y por lo tanto para los usuarios no son muy atractivos, el promocionar una tienda online requiere de mucho trabajo para que logre resultados positivos, y si no se cuenta con las herramientas necesarias esta no funciona. $Y$ aunque en esta época todo de base en tecnología existe personas que no cuentan con el acceso a un aparato inteligente que les brinde ser parte de esa actividad.

\section{Conclusion}

Sin duda alguna el comercio electrónico es una de las herramientas más importantes para la comercialización a nivel mundial, pues nos brinda un crecimiento y desarrollo a la sociedad. Pero para ello debemos ser conscientes de lo que implica participar en una actividad como esta, no solo se trata de subir a una página web la imagen o ilustración de algún producto, sino todo lo que se deriva de ello, determinar cada una de las variables que repercuten es su comercialización, como que tipo de publicidad se le brindara a los usuarios sobre este, las distintas modalidades de adquisición y envió, entre otras.

Así mismo tomar en cuenta cada una de las ventajas y desventajas que proporciona el comercio electrónico, no solo se debe realizar compras o ventas en algún sitio web, sino también saber dónde se debe buscar, como y para qué. No todo lo que se encuentra en la red es confiable o incluso legal. Para ello debemos informarnos, investigar sobre aquellas plataformas en las cuales se pueden comercializar productos de manera confiable, rápida y a un precio accesible.

El mercado, la tecnología y los seres humanos seguirán evolucionando, y con ellos las necesidades, la apertura de nuevas formas de comercializar son un beneficio para cada uno de ellos, es evidente que la unión de estos 3 factores es fundamental para que el crecimiento y desarrollo de un país prevalezca. Pero te has preguntado ¿Qué pasaría si alguna de estas 3 variables dejara de funcionar? Podríamos considerar 2 cosas: volver a la era del comercio tradicional, es decir, continuar con nuestras compras en forma física, observar y buscar cada uno de nuestros productos o que los seres humanos contribuyan para innovar estrategias que nos proporcione los mismos o mejores servicios que ahora.

\section{Referencias}

[1] Linkoo. (22 de octubre de 2012). Historia del comercio electronico. Obtenido de https://www.lynkoo.com/la-historia-del-comercioelectronico/

[2] Ríos Ruiz, A. d. (diciembre de 2014). Análisis y perspectiva del comercio electrónico en México. Obtenido de http://www.redalyc.org/articulo.oa?id=82332932006

[3] Rodríguez, E. M. (22 de noviembre de 2013). Actualidad Ecommerce. Obtenido de https://www.actualidadecommerce.com/ventajas-ydesventajas-del-ecommerce-frente-al-comercio-tradicional/ 